\title{
Primer trasplante renal en Colombia en paciente con infección por VIH
}

\section{First kidney transplant in Colombia in a patient with HIV infection}

\author{
Paola García, Mario Munévar, Carlos Benavides, Kateir Contreras \\ - Bogotá D.C., Colombia
}

\section{Resumen}

La infección por el virus de la inmunodeficiencia adquirida (VIH) ha aumentado su prevalencia a nivel mundial, la tercera parte de los pacientes desarrollan compromiso de la función renal y pueden llegar a requerir terapia de reemplazo renal. La terapia antirretroviral altamente efectiva (HAART) ha mejorado la supervivencia de los pacientes con dicha infección y ha motivado que esta población sea hoy considerada para ingresar a lista de trasplantes. Presentamos el caso de un paciente con enfermedad renal crónica secundaria a toxicidad por indinavir, quien permaneció durante cuatro años en hemodiálisis y recibe injerto renal de donante vivo, ha tenido seguimiento durante siete años con evolución favorable, sin rechazo, infecciones oportunistas ni complicaciones cardiovasculares, en manejo con terapia HAART logrando óptimo control virológico e inmunológico. La infección por VIH no es una contraindicación para recibir un trasplante renal y contribuye a mejorar calidad de vida y morbimortalidad en esta población. (Acta Med Colomb 2015; 40: 162-165).

Palabras claves: trasplante renal, VIH, terapia antirretroviral altamente efectiva, enfermedad renal crónica.

\begin{abstract}
Infection by human immunodeficiency virus (HIV) has increased its prevalence worldwide. One third of patients develop renal function involvement and might require renal replacement therapy. The highly active antiretroviral therapy (HAART) has improved survival of patients with this infection and this has motivated that this population be now considered for entering a transplant list. We report the case of a patient with chronic kidney disease secondary to toxicity by indinavir, who spent four years in hemodialysis and receives renal graft from living donor, has been followed up for 7 years with favorable evolution, without rejection, opportunistic infections or cardiovascular complications, and is being managed with HAART achieving optimal virological and immunological control. HIV infection is not a contraindication for renal transplantation and contributes to improving quality of life, morbidity and mortality in this population. (Acta Med Colomb 2015; 40: 162-165).

Keywords: kidney transplantation, HIV, highly active antiretroviral therapy, chronic renal disease.
\end{abstract}

Dres. Paola García, Mario Munévar, Carlos Benavides y Kateir Contreras: Hospital Universitario San Ignacio, Facultad de Medicina, Pontificia Universidad Javeriana. Bogotá D.C. (Colombia)

Correspondencia. Dra. Paola García. Bogotá D.C. (Colombia).

E-mail: pkgarcia@husi.org.co

Recibido: 14/IX/2014 Aceptado: 23/IV/2015

\section{Presentación del caso}

Presentamos el caso de un paciente masculino de 36 años, con antecedente de infección por virus de inmunodeficiencia humana (VIH) e hipertensión arterial, con enfermedad renal crónica (ERC) secundaria a toxicidad renal por indinavir diagnosticada en el año 2002 que progresa a estado 5 , requiriendo hemodiálisis durante cuatro años, llevado a trasplante renal con donante vivo en el Hospital Universitario San Ignacio (HUSI) en junio de 2007.

El diagnóstico de infección por VIH fue realizado en 1995; sin embargo, sólo desde 2001 inició tratamiento con terapia antirretroviral zidovudina (AZT), lamivudina (3TC), indinavir y ritonavir que posteriormente le fue cambiado por el esquema AZT, 3TC y nevirapina, por la toxicidad presentada con indinavir.

Dentro del estudio pretrasplante se realizó carga viral para VIH, la cual fue indetectable, recuento CD4 de 890 células $/ \mathrm{mm}^{3}$, anticuerpos IgG contra citomegalovirus positivo, anticuerpos contra hepatitis $\mathrm{C}$ negativos y antígeno de superficie del virus de hepatitis B negativo. El paciente fue considerado apto para trasplante renal. Su hermana de 29 años fue estudiada para donante vivo e igualmente se 
consideró apta. Se trasplantó con Missmatch de 2. Durante el trasplante recibió inducción con basiliximab $20 \mathrm{mg}$, día 0 y 4, metilprednisolona $500 \mathrm{mg}$ día $0,250 \mathrm{mg}$ día uno y $125 \mathrm{mg}$ día dos, y posteriormente prednisolona $30 \mathrm{mg} /$ día, micofenolato mofetilo $1 \mathrm{~g} / 12$ horas y ciclosporina $50 \mathrm{mg} / 12$ horas.

Presentó diuresis adecuada desde el intraoperatorio, que se acompañó de descenso progresivo de las cifras de azoados, con creatinina inicial de $10.7 \mathrm{mg} / \mathrm{dL}$ y al tercer día posoperatorio $2 \mathrm{mg} / \mathrm{dL}$.

Se observó dificultad en alcanzar los niveles de ciclosporina, probablemente debido a la interacción con nevirapina, por lo cual se cambió la inmunosupresión a tacrolimus $3 \mathrm{mg} \mathrm{VO} / 12$ h. La creatinina disminuyó a $1.5 \mathrm{mg} / \mathrm{dL}$ al sexto día del trasplante (Tabla 1). Adicionalmente continuó con micofenolato mofetilo y con descenso progresivo de la dosis de prednisolona hasta recibir $5 \mathrm{mg}$ al tercer mes del trasplante. Recibió profilaxis con nistatina $10 \mathrm{~mL} / 8$ horas durante tres meses, valganciclovir $450 \mathrm{mg}$ /día por tres meses y trimetoprim sulfametoxazol $160 / 800 \mathrm{mg}$ interdiario por seis meses.

Durante su seguimiento en estos siete años, la función renal ha permanecido estable, nunca ha presentado rechazo agudo celular, ni infecciones oportunistas. La filtración glomerular calculada por MDRD al año de trasplante fue de $45.3 / \mathrm{mL} / \mathrm{min} / 1,73 \mathrm{~m}^{2} \mathrm{SC}$, al segundo año $72 \mathrm{~mL} / \mathrm{min} / 1.73 \mathrm{~m}^{2} \mathrm{SC}$ y se ha mantenido cercana a este valor con una creatinina actual de $1.23 \mathrm{mg} / \mathrm{dL}$. La infección por VIH ha estado controlada con carga viral indetectable y últimos CD4 en 470 células $/ \mathrm{mm}^{3}$. El perfil lipídico muestra LDL $88 \mathrm{mg} / \mathrm{dL}$, con HDL $43 \mathrm{mg} / \mathrm{dL}$ y triglicéridos $226.6 \mathrm{mg} / \mathrm{dL}$, no ha presentado hiperglicemia y no ha requerido hospitalizaciones durante el seguimiento.

Actualmente recibe tratamiento inmunosupresor con tacrolimus de liberación prolongada (XL) $5 \mathrm{mg} /$ día, micofenolato mofetil $500 \mathrm{mg} / 12$ horas, prednisolona $2.5 \mathrm{mg}$ interdiarios y HAART con raltegravir $400 \mathrm{mg} / 24$ horas y abacavir/lamivudina 600/300 mg/12 horas.

Tabla 1. Evolución de azoados, niveles séricos de tacrolimus, carga viral y CD4 en postrasplante.

\begin{tabular}{|l|c|c|c|c|}
\hline & Creatinina & $\begin{array}{c}\text { Niveles de } \\
\text { tacrolimus }\end{array}$ & Carga viral & CD4 \\
\hline Mes 1 & 1.8 & 8.9 & Indetectable & 818 \\
Mes 6 & 1.5 & 9.5 & Indetectable & $>500$ \\
Mes 12 & 1.2 & ND & ND & ND \\
Mes 24 & 1.1 & 8.3 & ND & ND \\
Mes 36 & 1.1 & 5.1 & Indetectable & 560 \\
Mes 48 & 1.1 & 4.7 & Indetectable & 650 \\
Mes 60 & 1.1 & 4.7 & ND & ND \\
Mes 72 & 1.23 & 5.0 & indetectable & 470 \\
\hline ND: No disponible & \multicolumn{5}{|l}{} \\
\hline
\end{tabular}

\section{Discusión}

La prevalencia de infección por el VIH en las unidades de hemodiálisis es muy variable a nivel mundial. Las diferentes encuestas publicadas en los años ochenta y principios de los noventa, muestran un rango muy amplio, desde $0 \%$ en unidades de hemodiálisis de países como Japón hasta $39 \%$ en algunas unidades de hemodiálisis en Brooklyn (Nueva York, EE.UU.) (1, 2).

Hasta hace unos años la infección por VIH constituía una contraindicación absoluta para la realización de cualquier tipo de trasplante ante el temor de incrementar las complicaciones derivadas de la terapia inmunosupresora, utilizar órganos escasos con resultados a largo plazo desconocidos y el riesgo de transmisión viral al grupo médico entre otros $(3,4)$. Desde la primera descripción de la enfermedad, el compromiso renal permanece como una importante causa de morbimortalidad en los pacientes infectados con VIH, afecta una tercera parte de ellos y muestra un amplio espectro que abarca lesiones primarias de comportamiento agresivo como la glomeruloesclerosis focal y segmentaria asociada al VIH (HIVAN), glomerulonefritis mediadas por complejos inmunes, microangiopatía trombótica y nefrotoxicidad generada por algunos medicamentos antirretrovirales $(1,2)$.

A partir de 1996 y tras la introducción de la terapia HAART, el curso clínico de la infección por el VIH ha cambiado de forma significativa, con descenso de la morbilidad por procesos oportunistas y de la mortalidad global de los pacientes con síndrome de inmunodeficiencia adquirida (SIDA) (5).Esta mejoría en el pronóstico ha hecho que exista una mayor mortalidad por enfermedad orgánica terminal que por infecciones oportunistas o neoplasias asociadas al SIDA (6).

Lo anterior implica la necesidad de un nuevo planteamiento en el tratamiento a largo plazo de los pacientes infectados por el VIH y ERC, de tal manera que en la actualidad, la infección por el VIH ha dejado de ser una contraindicación absoluta para el trasplante renal (5).

En la década de los años ochenta, la mayoría de pacientes infectados por el VIH con ERC presentaban un estado avanzado de la infección y una supervivencia media muy corta, entre 1 y 13 meses. Estos pacientes frecuentemente tenían caquexia y malnutrición y las principales causas de muerte eran infecciones oportunistas y/o enfermedades malignas (2).

En la década de los años noventa, hubo estudios que pusieron de manifiesto un progresivo aumento de supervivencia con medias hasta de 57 meses incluso en aquellos pacientes con edad más avanzada y con una elevada prevalencia de diabetes (7).

Se han identificado varios factores que contribuyen a mejorar el pronóstico de estos pacientes en hemodiálisis: mejor soporte nutricional, mejoras en la terapia de diálisis, corrección de la anemia con eritropoyetina, inicio del tratamiento antirretroviral y la profilaxis de las infecciones oportunistas (1). 
Existen algunos estudios que evidencian una correlación positiva entre la cifra de linfocitos CD4 y la supervivencia de los pacientes infectados por el VIH en hemodiálisis (8). Otros estudios han sugerido una mayor supervivencia de los pacientes que están bajo tratamiento con HAART en comparación con los que no la reciben $(1,9)$.

Antes del uso de la terapia HAART, la experiencia en trasplante renal en el paciente infectado por el VIH, mostraba un pronóstico subóptimo y en su gran mayoría provenían de donante cadavérico (1).

Hasta mediados de los años noventa, se documentaron casos de infección de novo por VIH en receptores de órganos infectados o por desarrollo de la infección después del trasplante. Esto se debió a que muchos de estos se realizaron sin conocer el estado virológico e inmunológico del paciente (1). Al realizar el seguimiento de esos pacientes, se encontró mayor progresión a SIDA en comparación con los no trasplantados, y la supervivencia postrasplante, era menor comparado con aquellos sin infección por el VIH, debido a complicaciones derivadas de infecciones oportunistas asociadas al SIDA. Desde el desarrollo de la terapia HAART, se han publicado series de casos y estudios retrospectivos con buenos resultados a corto y mediano plazo y mayor número de trasplantes con donante vivo $(6,9)$.

Los criterios para seleccionar pacientes para trasplante renal, son similares en los diferentes grupos de trasplante: ausencia de manifestaciones oportunistas definitorias de SIDA, recuento de linfocitos CD4+ > 200 células $/ \mathrm{mm}^{3}$ y carga viral plasmática del VIH indetectable $(1,10)$.

La supervivencia encontrada a corto y mediano plazo de los pacientes infectados por VIH que reciben un injerto renal, es similar a la de los no infectados. El trasplante renal no conlleva mayor progresión de la infección por el $\mathrm{VIH}$, aumento en el número de infecciones oportunistas o aumento en la incidencia de neoplasias relacionadas con el SIDA; adicionalmente es posible mantener un buen control virológico e inmunológico de la infección por el VIH mediante la administración de terapia HAART en el periodo postrasplante (6).

Sin embargo, se ha documentado mayor incidencia de rechazo agudo del injerto en los pacientes infectados por el VIH (52\% a un año y 70\% a tres años), pero sin impacto sobre la supervivencia del paciente y del injerto, a tres años se mantienen en 94 y $83 \%$ respectivamente (1). Hay mayor incidencia de disfunción retardada del injerto y mayor deterioro de la función renal cuando hay coinfección con hepatitis C (5). La etiología de estos hallazgos es incierta, se han propuesto la desregulación del sistema inmune y la inmunosupresión insuficiente como posibles causas, pero este sigue siendo un campo abierto a la investigación (1).

Dada la reciente inclusión de los pacientes con infección por VIH a listas de espera de trasplante renal, se han venido modificando los criterios de ingreso a ésta y la recomendación es realizar el protocolo usual de pacientes candidatos a trasplante renal, teniendo en cuenta aspectos psicosociales, clínicos, inmunológicos y virológicos particulares de esta población de pacientes (1).

Está contraindicado el uso de injertos de pacientes infectados por VIH por la variedad de cepas y el riesgo de transmitirlos, a excepción de Sudáfrica, donde la disponibilidad de diálisis es limitada y hay reportes que sugieren resultados exitosos con donantes VIH positivos en receptores VIH positivos (11).

Con respecto a la terapia inmunosupresora, muchos agentes utilizados tienen propiedades antirretrovirales. Micofenolato mofetilo tiene acción virostática resultado de la disminución de los nucléosidos de guanosina que son necesarios para el ciclo de vida del virus. Ciclosporina y tacrolimus inhiben selectivamente el crecimiento de células infectadas e interfieren con la función de las proteínas patogénicas del VIH que resulta en la reducción de la formación del virus. El sirolimus permanece como una alternativa, suprime la activación de células $\mathrm{T}$, la función de las células presentadoras de antígeno e interviene en la disrupción de la replicación del virión (10).

En cuanto a la inducción, se ha utilizado basiliximab, sin embargo, dada la alta incidencia de rechazo agudo, algunos prefieren utilizar agentes depletores de linfocitos como timoglobulina (1), en nuestro caso se utilizó basiliximab obteniendo un resultado adecuado.

El esquema HAART debe reiniciarse en el posoperatorio tan pronto como sea posible. Se deben procurar los esquemas con menores interacciones farmacológicas con los inmunosupresores $\mathrm{y}$, de ser posible, que no incluyan fármacos potencialmente nefrotóxicos y que sean de fácil cumplimiento $(1,10)$. Debe realizarse monitorización estrecha de las concentraciones plasmáticas de inmunosupresores (2, 6). Algunos reportes han sugerido que raltegravir, medicamento que recibe actualmente nuestro paciente, tiene menor probabilidad de interacciones farmacológicas.

Igualmente es fundamental la adherencia al tratamiento, uno de los objetivos principales de la evaluación psicosocial pretrasplante es establecer el grado de adherencia del paciente a tratamientos previos, ya que el no cumplimiento de los estrictos controles luego del trasplante puede desencadenar toxicidad grave, complicaciones infecciosas o aún la pérdida del injerto (6). Luego del trasplante renal los pacientes deben recibir una gran cantidad de medicamentos que pueden comprometer la adherencia (1).

La terapia HAART al igual que la terapia inmunosupresora puede inducir resistencia a la insulina, diabetes mellitus, hipertensión y dislipidemia, conocidos factores de riesgo cardiovascular por lo que debe hacerse seguimiento y manejo oportuno (2).

Algunos antirretrovirales tienen riesgo de generar nefrotoxicidad, indinavir se asocia a un mayor riesgo de nefrolitiasis y tenofovir con deterioro de la función renal y tubulopatías, principalmente síndrome Fanconi-like $(1,6)$.

Estos pacientes deben recibir los mismos regímenes de profilaxis que los pacientes VIH negativos. Se recomienda 
retomarla en los periodos de mayor inmunosupresión: primer mes postrasplante, posterior al tratamiento de rechazo y cada vez que descienda el recuento de CD4 por debajo del límite considerado de riesgo para cada infección. Debe realizarse vigilancia clínica y virológica adecuada para diagnosticar y tratar precozmente las posibles infecciones (10).

Este caso corresponde al primer paciente con infección por VIH que se trasplantó en Colombia, recibió terapia de inducción con basiliximab y terapia de mantenimiento con tacrolimus, micofenolato mofetilo y prednisolona, asociado a terapia antirretroviral, similar a lo descrito en la literatura. No ha presentado episodios de rechazo durante su seguimiento a siete años, ha conservado adecuada función del injerto, no ha presentado complicaciones cardiovasculares y permanece con adecuado control de su enfermedad de base, sin procesos infecciosos oportunistas ni tumorales. Concluimos que el trasplante renal es una alternativa de tratamiento para pacientes con VIH y ERC en nuestro país, que mejora su calidad de vida y supervivencia, similar a la población sin infección por VIH.

\section{Conflicto de intereses}

Los autores declaran no tener conflictos de intereses relacionados con el presente manuscrito.

\section{Financiación}

Esta presentación de caso no contó con financiación para su realización.

\section{Referencias}

1. Trullas JC, Cofan F, Tuset M, Ricart MJ, Brunet M, Cervera C, et al. Renal transplantation in HIV-infected patients: 2010 update. Kidney Int. 2011; 79 (8):82542.

2. Feinfeld DA, Kaplan R, Dressler R, Lynn RI. Survival of human immunodeficiency virus-infected patients on maintenance dialysis. Clin Nephrol. 1989; 32:221-4.

3. Gómez V, Fernández A, Galeano C, Oliva J, Diez V, Bueno C, et al. Renal transplantation in HIV-infected patients: experience at a tertiary hospital in Spain and review of the literature. Transplant Proc. 2013; 45(3): 1255-9

4. Frassetto LA, Tan-Tam C, Stock PG. Renal transplantation in patients with HIV. Nat Rev Nephrol. 2009; 5(10): 582-9

5. Stock PG, Barin B, Murphy B, Hanto D, Diego JM, Light J, et al. Outcomes of kidney transplantation in HIV-infected recipients. $N$ Engl J Med. 2010; 363(21): 2004-14.

6. Reese PP, Blumberg EA, Bloom RD. Kidney transplantation in patients with HIV infection. Adv Chronic Kidney Dis. 2010; 17(1): 94-101

7. Rao TK, Manis T, Friedman EA. Dismal prognosis despite maintenance hemodialysis in AIDS nephropathy and chronic uremia. Trans Am Soc Artif Intern Organs. 1985; 31:160-3.

8. Tourret J, Tostivint I, du Montcel ST, Bragg-Gresham J, Karie S, Vigneau C, et al. Outcome and prognosis factors in HIV-infected hemodialysis patients. Clin J Am Soc Nephrol. 2006; 1(6): 1241-7

9. Mazuecos A, Pascual J, Gómez E, Sola E, Cofán F, López F, et al. Renal transplantation in HIV-infected in Spain. Nefrología. 2006; 26(1): 113-20

10. Moreno CN, Siqueira RC, Noronha IL. Kidney transplantation in HIV infected patients. Rev Assoc Med Bras. 2011; 57(1):100-6.

11. Muller E, Barday Z, Mendelson M, Kahn D. HIV-positive-to-HIV-positive kidney transplantation--results at 3 to 5 years. N Engl J Med. 2015; 372(7): 613-20 